\title{
Aa. Vv., «Cultures Sud», Caraibes: un monde à partager, n. 168
}

\section{Luigia Pattano}

\section{Q OpenEdition}

1 Journals

\section{Edizione digitale}

URL: http://journals.openedition.org/studifrancesi/8098

DOI: 10.4000/studifrancesi.8098

ISSN: 2421-5856

\section{Editore}

Rosenberg \& Sellier

\section{Edizione cartacea}

Data di pubblicazione: 1 juillet 2009

Paginazione: 447-448

ISSN: 0039-2944

\section{Notizia bibliografica digitale}

Luigia Pattano, «Aa. VV., «Cultures Sud», Caraïbes: un monde à partager, n. 168», Studi Francesi [Online], 158 (LIII | II) | 2009, online dal 30 novembre 2015, consultato il 12 janvier 2021. URL: http:// journals.openedition.org/studifrancesi/8098; DOI: https://doi.org/10.4000/studifrancesi.8098

Questo documento è stato generato automaticamente il 12 janvier 2021.

\section{(c) (i) $\odot$}

Studi Francesi è distribuita con Licenza Creative Commons Attribuzione - Non commerciale - Non opere derivate 4.0 Internazionale. 


\title{
Aa. Vv., «Cultures Sud», Caraibes: un monde à partager, n. 168
}

\author{
Luigia Pattano
}

\section{NOTIZIA}

«Cultures Sud», Caraibes: un monde à partager, n. 168, gennaio-marzo 2008, pp. 397

1 «Vibrante omaggio a tutti i grandi teorici e artisti del pensiero caraibico», il numero $168 \mathrm{di}$ «Cultures Sud» è consacrato interamente alle giornate che hanno inaugurato il progetto di «Caraïbes en Créations», programma triennale finanziato e diretto da Culturesfrance che mira a incoraggiare la cooperazione e a promuovere l'industria culturale nell'area caraibica (insulare e continentale) perché i suoi prodotti siano accessibili in egual misura a tutti da un capo all'altro dei Caraibi. Il volume, la cui ottica plurale e multifocale è esemplificata dalla traduzione di ogni intervento nelle lingue principali della regione (francese, inglese e spagnolo) e dal dvd che, con le sue componenti sonora e visiva, integra splendidamente i testi, traduce propriamente lo spirito all'origine delle iniziative che hanno lanciato il progetto, denominate, con un tocco di fiduciosa ambizione, «Rencontres fondatrices». Svoltisi nel giugno 2007 a CapHaïtien (repubblica di Haiti), questi incontri fondatori hanno portato decine e decine di artisti, scrittori e musicisti caraibici a confrontarsi in un luogo altamente simbolico: la citadelle Henry, fortezza eretta dal re Christophe per resistere all'offensiva francese all'epoca gloriosa delle rivolte per l'indipendenza dell'isola. Preoccupazione centrale dei partecipanti è, naturalmente, il problema identitario - «cette insaisissable conscience caraïbe» che dà il titolo all'editoriale -, problema che non può essere taciuto né dato per scontato in una regione caratterizzata in maniera evidente e a vari livelli da molteplicità e diversità. Particolarmente pertinente al discorso identitario è il raffronto evocato da Jean BERNABÉ (pp. 82-93) tra la situazione linguistica dei Caraibi, in tutti i territori diversa eppur parimenti molteplice e complessa, e il paradosso inerente al linguaggio, caratterizzato al contempo da unità e diversità. Solo postulando un'«unità nella diversità» è possibile elaborare un discorso identitario comune che non annulli le 
differenze riconducendo tutto all'Uno come avviene in quel che GLISSANT definisce «pensiero continentale» in opposizione al «pensiero arcipelagico». Quel che legittima inoltre la possibilità di prefigurare un progetto culturale unitario è, secondo diversi autori tra cui Lyonel trouilLot e Marcio Veloz MAGGiolo, il fatto di aver condiviso uno stesso passato traumatico: quello della colonizzazione e della schiavitù. L'intervento di Trouillot si distingue in particolare per lo sguardo impietoso e amaro gettato sulla realtà dei Caraibi: per lo scrittore haitiano è attualmente impossibile fondare un'identità caraibica dal momento che tra le popolazioni manca la consapevolezza diffusa di aver attraversato un medesimo processo. Tale impossibilità perdurerà finché ogni comunità, ogni isola «sera condamné à penser son identité dans l'ignorance de l'histoire des autres» (p.76). Non occorre dunque tanto dimostrare l'unità caraibica quanto invece colmare il deficit storico da cui è affetta la regione. Mostrando una posizione molto simile a quella di Trouillot, l'autore dominicano sostiene la necessità di avviare un progetto di unificazione del discorso storico che consenta di creare un'identità comune a partire dall'integrazione delle storie locali. Accanto agli interventi teorici sulla questione identitaria, raccolti nella prima sezione, il volume intende mostrare la ricchezza delle varie espressioni artistiche prodotte nel bacino caraibico. Lo spazio maggiore è dedicato alla letteratura, che in quest'area ha prodotto alcuni dei testi contemporanei più pregevoli scritti nelle lingue europee introdotte durante la colonizzazione, ma si segnalano anche interventi legati ad altri temi: creoli e creolizzazioni, multiculturalismo, esilio e diaspora, musica, alcune problematiche relative alla scarsa diffusione della cultura. Intervallato da recensioni e schede di lettura, il dossier si chiude con una sezione di scritti inediti firmati da alcuni grandi nomi della regione: Dingo, Frankétienne, Earl Lovelace, Marcio Veloz Maggiolo, Guy Régis Jr., Simone Schwarz-Bart, Elizabeth Walcott e Ariel Felipe Wood. 